\title{
PERFORMANCE OF FRP-RETROFITTED CONCRETE BRIDGE COLUMNS UNDER BLAST LOADING
}

\author{
R. ZHENG ${ }^{1}$, P. ZOHREVAND ${ }^{2}$, H. ERDOGAN ${ }^{3}$ \& A. MIRMIRAN ${ }^{2}$ \\ ${ }^{1}$ Aker Marine Contractors US, Inc., 2103 City West Blvd., Houston, TX, USA. \\ ${ }^{2}$ Department of Civil and Environmental Engineering, Florida International University, Miami, FL, USA. \\ ${ }^{3}$ Department of Civil Engineering, Kocaeli University, Kocaeli, Turkey.
}

\begin{abstract}
Contrary to military or essential government buildings, most bridges are designed without any consideration for blast resistance. Fiber-reinforced polymers (FRPs) can provide an effective means for strengthening of critical bridges against such loading. This study has focused on the effectiveness of FRP retrofitting in the dynamic response of reinforced concrete bridge columns under blast loading. Using a simplified equivalent I-section with a virtual material lumped at the two flanges; a lightly meshed uniaxial finite element model was developed and successfully validated against previous studies. The proposed model was then used for a thorough parametric study on the blast resistance of bridge substructures in the form of a single-column, two-column pier frame, and an entire bridge. The study showed the benefits of strengthening with composites against blast loading. The FRP tensile strength and diameter-to-thickness ratio, steel reinforcement ratio, and column length and damping ratio significantly affect the blast resistance of an FRP-retrofitted bridge. Finally, based on the parametric study results, predictive equations with multiple linear regression and high order terms were developed statistically for the FRP retrofit design of single columns against blast loading.

Keywords: Blast, bridges, concrete, fiber-reinforced polymer (FRP), finite element modeling, retrofit.
\end{abstract}

\section{INTRODUCTION}

In the face of terrorist attacks on landmark buildings and threats against vital lifeline bridges, security of transportation arteries is of grave concern. Contrary to military or essential government buildings, most bridges are designed without any consideration for blast resistance [1,2]. Crucial bridge components such as reinforced concrete (RC) girders and columns are vulnerable to large blast loads from close-by explosions, leading to progressive span collapse or catastrophic shearing off of columns. Therefore, it is imperative to develop techniques to harden critical bridges against potential blast loading.

The use of fiber-reinforced polymers (FRPs) for retrofitting of RC buildings to resist explosions has gained interest since the Oklahoma City bombing [3,4]. FRP wraps can confine RC columns susceptible to shearing off by blast impulse, enhance their capacity, and limit their lateral deflections. The use of FRP sleeves or tubes in new columns and piles has also proven effective under impact and seismic loads [5-7]. A number of studies have assessed the effect of FRP retrofitting on the dynamic response of RC structures. Elsanadedy et al. studied the effect of carbon (C) FRP retrofitting on the blast resistance of RC circular columns [8]. Their results showed that CFRP retrofitting can significantly decrease the blast damage and maximum lateral deflection experienced by $\mathrm{RC}$ columns under explosions. Crawford et al. developed a design procedure for using steel jackets and FRP wraps to improve the survivability of RC columns under blast loading [9]. Williamson and Winget discussed the potential effects of blast loads on bridges, provided structural design and retrofit solutions to counter those effects, and suggested the use of FRP wraps or steel jackets to enhance shear and flexural strength and to control lateral deflections [10]. Hamed and Rabinovitch studied the behavior of RC beams strengthened with externally bonded FRP under 
different dynamic loads (including impulse loads) using an analytical model based on dynamic equilibrium, deformation compatibility, and higher order theory [11]. Mosalam and Mosallam developed a finite element (FE) model to study the blast impact on two-way RC slabs with and without externally bonded carbon FRP strips [12].

Laboratory and full-scale blast experiments on retrofitted RC members have been few and limited due to the complexity of explosive testing of different structural systems. Most studies in this area apply analytical simulations. Current analytical work in blast loading mostly applies 3-D complex FE modeling schemes, accuracy of which depends greatly on the fineness of the mesh, which in turn leads to significantly high computational cost [13-15].

This study assesses the effectiveness of FRP retrofit measures for strengthening of RC bridge structures. It further investigates the effect of different design parameters, such as FRP type and thickness, steel reinforcement ratio, configuration of the structure, bomb size, and damping ratio, on the blast resistance of FRP-retrofitted RC bridges using a verified novel analytical model. Accordingly, the results of this study can be used for the design of FRP retrofitting of $\mathrm{RC}$ structures, especially bridges, to make them adequately resistant against explosions and terrorist attacks. Also, the simplified analytical approach proposed in this paper enables engineers to do such designs easier and faster with high fidelity, as compared with the existing elaborate analytical FE approaches.

\section{ANALYTICAL MODELING}

\subsection{Simplified finite element modeling}

A typical FRP-retrofitted RC (FRRC) section can be discretized into a number of integration strips (Fig. 1). For each strip, the respective constitutive models are utilized. The interaction amongst the different materials (e.g. confinement effects) is considered implicitly at the materials level and not in the sectional analysis. To simplify the complex blast analysis with high fidelity and no loss of accuracy, this study incorporates the concept of using an equivalent section with a virtual material that would generate the same moment-curvature as that of the original section. Hence, an equivalent section is proposed to transform the existing section geometry into an I-shaped section (Fig. 2), whereby the web thickness is considered to be negligible, and the entire section is lumped into two flanges with finite small thickness, limiting the stress variation within the flange thickness. Since the virtual material is only present at the top and bottom of the section, there is no strain or stress gradient in the section. With the concept of equivalent section, the section performance is fingerprinted by the stressstrain curve of the virtual material defined at the two flanges. The stress-strain curve of the virtual material should be defined directly from the moment-curvature response of the original cross section. Accordingly, the moment-curvature response of the original cross section

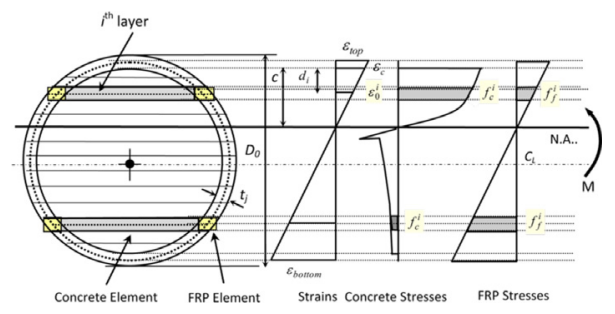

Figure 1: Illustration of sectional analysis using strip method. 


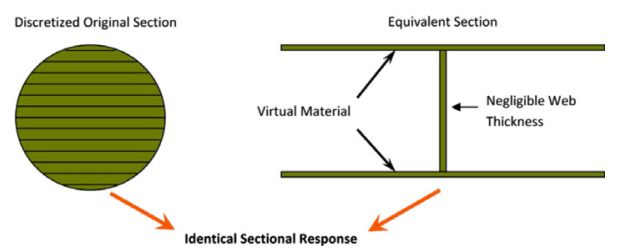

Figure 2: Illustration of the equivalent section concept.

is first obtained based on the constitutive material models using a sectional analysis software, e.g. RESPONSE 2000 [16]. Then, the stress-strain curve of the virtual material for the equivalent I-shaped section is defined based on the sectional moment-curvature response. The equivalent I-section and virtual material properties are then assigned to the FE members of the structural model generated in a general-purpose FE software, e.g. ANSYS 8.0, to perform dynamic analysis representing blast loading [17].

\subsection{Constitutive material modeling under high strain rates}

Blast loads typically produce very high strain rates in the range of $10^{2}$ to $10^{4} \mathrm{~s}^{1}$. This high straining rate would significantly increase the stress and strain capacities of concrete and steel reinforcement, and accordingly affects the dynamic performance of the target structure [15]. Below, the dynamic effects on each of the materials are discussed separately.

\subsubsection{Concrete}

The dynamic effect is introduced into the concrete model using the factor $K_{d}$ [18], as:

$$
\begin{gathered}
K_{d}(\dot{\varepsilon})=\left(\frac{\dot{\varepsilon}}{\dot{\varepsilon}_{s}}\right)^{1.026 a} \text { for } \dot{\varepsilon} \leq 30 \mathrm{~s}^{-1} \\
K_{d}(\dot{\varepsilon})=\nu\left(\frac{\dot{\varepsilon}}{\dot{\varepsilon}_{s}}\right)^{1 / 3} \text { for } \dot{\varepsilon}>30 \mathrm{~s}^{-1} \\
\log \gamma=6.156 a-2 \\
a=1 /\left(5+9 f_{c}^{\prime} / f_{c o}^{\prime}\right)
\end{gathered}
$$

where $\dot{\varepsilon}$ is the strain rate, $\dot{\varepsilon}_{s}$ (quasi-static strain rate) is $30 \times 10^{6} \mathrm{~s}^{1}, f^{\text {, }}$ co is the reference strength set as $10 \mathrm{MPa}$, and $f_{c}^{\prime}$ is the 28-day compressive strength of concrete at static strain rate. According to CEB-FIB 1990 [18], the increased compressive strength $\left(f_{c d}^{\prime}\right)$ of concrete under dynamic loading can be calculated as:

$$
f_{c d}^{\prime}=f_{c}^{\prime} K_{d}
$$

The strain at the peak stress also increases from $e_{c}$ to $e_{c d}$, which is also strain-rate dependent [19], as

$$
\varepsilon_{c d}=\left(0.12 K_{d}^{3}(\dot{\varepsilon})+0.76\right) \varepsilon_{c}
$$


The stress-strain relationship of concrete under dynamic loading can be further developed based on the modified Scott et al. model [20], as proposed by Ngo [19]:

$$
\begin{array}{lr}
f=K_{d} f_{c}^{\prime}\left[\frac{2 \varepsilon}{\varepsilon_{c d}}-\left(\frac{\varepsilon}{\varepsilon_{c d}}\right)^{2}\right] & \text { for } \quad \varepsilon \leq \varepsilon_{c d} \\
f=K_{d} f_{c}^{\prime}-Z_{d}\left(\varepsilon-\varepsilon_{c d}\right) & \text { for } \varepsilon>\varepsilon_{c d}
\end{array}
$$

where $f$ and $\varepsilon$ are the stress and strain of concrete, respectively, and $Z_{d}$ is the softening slope, defined as

$$
Z_{d}=\frac{K_{d} f_{c}^{\prime} Z}{\frac{3+0.29 f_{c}^{\prime}}{145 f_{c}^{\prime}-1000}+\frac{3}{4} \rho_{s} \sqrt{\frac{h^{\prime}}{s_{h}}}}\left(\frac{\dot{\varepsilon}}{\dot{\varepsilon}_{s}}\right)^{-0.1}
$$

where $Z$ is the softening slope of concrete at static strain rate, $\rho_{s}$ is the volumetric ratio of the hoop reinforcement relative to the concrete core area, $h^{\prime}$ is the width of concrete core measured to the outside of stirrups or hoops, and $s_{h}$ is the center-to-centerspacing of stirrups or hoops.

It should be mentioned that the confined concrete in this study is modeled using the modified Kent-Park model [20].

\subsubsection{Steel reinforcement}

Steel reinforcement also shows higher strength and ductility under high strain rate. Soroushian and Choi proposed a model for stress-strain response of steel under various loading rates [21]. They reported that the increases in steel yielding stress, ultimate strength, and ultimate strain are proportional to the logarithmic function of the strain rate, as follows:

$$
\begin{aligned}
& \frac{f_{y}^{\prime}}{f_{y}}=\left(-0.451 \times 10^{-6} f_{y}+1.46\right)+\left(-9.20 \times 10^{-7} f_{y}+0.093\right) \log _{10} \dot{\varepsilon} \\
& \frac{f_{p}^{\prime}}{f_{p}}=\left(-6.83 \times 10^{-6} f_{y}+1.72\right)+\left(-1.37 \times 10^{-6} f_{y}+0.144\right) \log _{10} \dot{\varepsilon} \\
& \frac{\varepsilon_{u}^{\prime}}{\varepsilon_{u}}=\left(-8.93 \times 10^{-6} f_{y}+1.4\right)+\left(-1.79 \times 10^{-6} f_{y}+0.083\right) \log _{10} \dot{\varepsilon}
\end{aligned}
$$

where $f_{y}, f_{p}$, and $e_{u}$ are the yielding strength, ultimate strength, and ultimate strain of steel reinforcement under static loading, respectively; and $f_{y}^{\prime}, f_{p}^{\prime}$, and $\varepsilon_{u}{ }_{u}$ are their corresponding values under high strain rate of $\dot{\varepsilon}$.

\subsubsection{FRP materials}

A uniaxial tri-linear hysteretic model was used to model the FRP tube, as proposed by Shao and Mirmiran [22]. According to Kuksenko and Tamuzs, FRP materials do not show significant strength gain under high strain rates [23]. As such, no dynamic effect was included for FRP materials in this study. 


\subsection{Modeling of blast loading}

The threat of a conventional bomb to a structure is mainly presented by the over-pressure on its surface. This is a complex mechanism depending on the geometry and composition of the structure, the magnitude and the angle of the blast wave, and relative distance of the blast. After the bomb is detonated, the blast pressure wave propagates in a hemispherical shape, decaying over the distance as the volume of the hemisphere grows proportional to the third order of the distance of the outermost surface to the epicentre of the bomb. The time frame for the blast load is very brief and concentrated, resulting in a large impact on the structure often lasting only a few milliseconds. Blast pressure on the structure ramps up to a peak value almost instantly upon the arrival of the pressure wave front. The pressure then decays exponentially and eventually becomes negative (suction) as presented in Fig. 3. A common practice for simulation of the blast pressure is to simplify the nonlinear curve with a triangular function, neglecting the negative phase of the blast load history (see Fig. 3). The two major factors controlling the blast load on a structure are bomb size, measured as charge weight $(W)$ of equivalent amount of TNT and the stand-off distance $(R)$ between the blast source and the target structure. In most studies in the literature, the blast pressure on a structure is simplified as a uniformly distributed load along the height of the structure, if the stand-off distance is relatively large with respect to the size of the target structure. Accordingly, the same assumption was used in this study. Software AT Blast was used to generate pressure-impulse histories for each blast loading condition in this study [24].

\subsection{Verification of the simplified FE model}

To verify the proposed simplified analytical model, a single-column structure that was previously studied by Ngo et al. under blast loading was considered in this study [25]. Accordingly, a ground floor column with a total height of $6.4 \mathrm{~m}$ and a rectangular section of $900 \mathrm{~mm} \times$ $500 \mathrm{~mm}$ (see Fig. 4) was modeled using the simplified FE modeling approach. The concrete strength of the column was $40 \mathrm{MPa}$. Steel bars of Nos 32 and12 were used as longitudinal and transverse reinforcement, respectively. The yield strength of all steel reinforcement was $414 \mathrm{MPa}$. The blast load was calculated using data from the 1995 Oklahoma bombing with a stand-off distance of $11.2 \mathrm{~m}$ [25].

The sectional moment-curvature (see Fig. 5a) was obtained using RESPONSE 2000 [16]. The constitutive model of the virtual material was developed for the equivalent section, as shown in Fig. 5b. The transient dynamic analysis was then carried out using ANSYS ${ }^{\circledR} 8.0$ [17]. Then, the column with the transformed cross section (equivalent I-section) and the specified virtual material was modeled using two-noded 3-D finite strain beam elements BEAM188. It

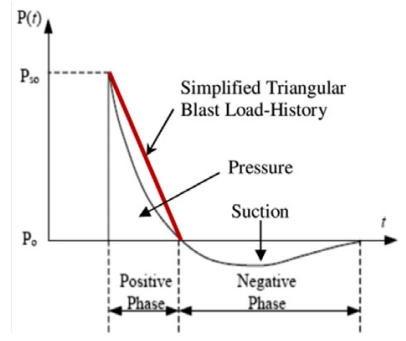

Figure 3: Blast load simulation. 
should be mentioned that only half of the column was modeled due to symmetric boundary conditions. The structural mass was modeled using MASS21 element, which is a single-noded element with concentrated mass components along (and rotary inertias about) the element coordinate axes. The finite mesh was established with 41 mass nodes and 40 finite strain beam elements, as shown in the inset of Fig. 6. The full transient dynamic method with a single-step procedure to calculate the displacements and stresses was used for the analysis. The solution of the equation of motion was based on the Newmark direct integration scheme with the Newton-Raphson method, which is an iterative procedure of solving nonlinear equations. The tolerance value of convergence criteria for the nonlinear analysis was set as 0.001 for the forces and moments.

The time history of lateral deflection at column mid-height is shown in Fig. 6, as compared with the results from Ngo et al. [25]. The comparison indicates the suitability of the proposed method for analyzing concrete structures under blast loading in a fraction of time needed for the complex 3-D analysis.

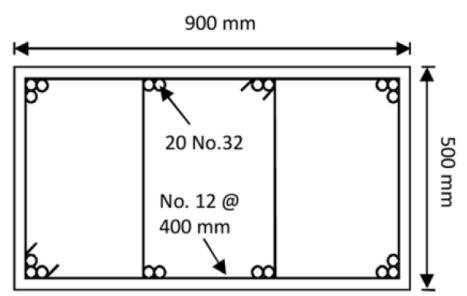

Figure 4: Cross-section of the column studied by Ngo et al. [25].
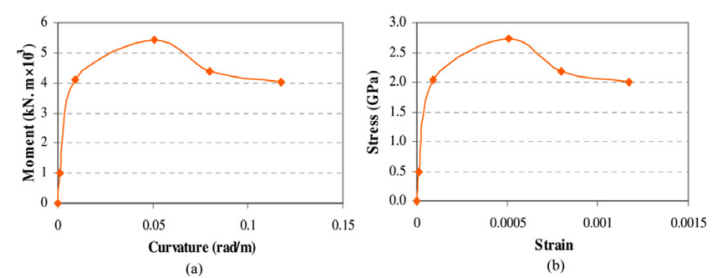

Figure 5: (a) Moment-curvature response of original section and (b) stress-strain response of the virtual material.

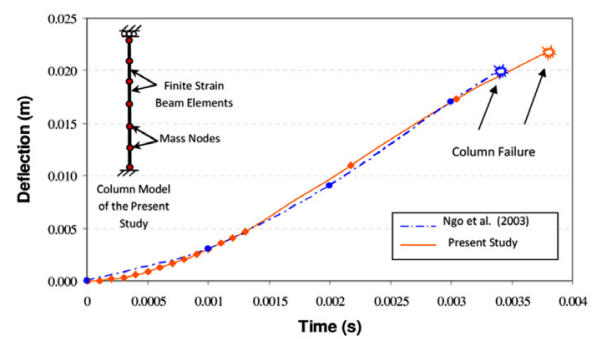

Figure 6: Comparison of lateral deflection-time histories at the column mid-height resulted from the present study and Ngo et al. [25]. 


\section{PARAMETRIC STUDY}

Using the verified FE analytical approach, three different FRP-retrofitted RC structural systems; single column, pier frame, and entire bridge, were modeled and simulated under blast loading and the effect of different parameters on their blast loading response was thoroughly investigated, as explained below:

\subsection{Single-column and pier frame models}

A single-column model with the same boundary conditions as those used in the previous section (verification of the analytical model) was used for the parametric study, as shown in Fig. 7(a). The pier frame model was adopted from the National Cooperative Highway Research Program (NCHRP) Project 12-49 [26].The weight of the superstructure was simulated with two constant axial loads on top of the two columns (see Fig. 7(b)). The top beam of the pier frame was modeled as a rigid beam element. The columns in both structural systems (single column and pier frame) were modeled using BEAM 199 elements, and the structural mass was modeled using mass nodes between beam elements. Both the column and pier frame models were two-dimensional to accommodate an in-plane analysis. The same analysis procedure was used as that applied in the verification part.

Two sets of parameters were considered for both single-column and two-column pier frame models (see Table 1): column parameters (column type, concrete strength, steel reinforcement ratio, FRP wrap diameter-to-thickness ratio, tensile strength of FRP, cross section geometry, column height, and damping ratio) and blast parameters (bomb size). Both FRP-retrofitted and non-retrofitted (reference) structures were investigated. Two types of cross sections, circular with a diameter of $387.5 \mathrm{~mm}$ and rectangular with the dimensions of $900 \mathrm{~mm} \times 500 \mathrm{~mm}$, were considered for the column members. The longitudinal steel reinforcement ratio was ranging between $1.26 \%$ and $3.6 \%$. The transverse steel reinforcement was eliminated in FRP-retrofitted columns. The same transverse steel reinforcement was used for rectangular RC columns as that used for the column model in the previous section (see Fig. 4), while No. 12 spiral at 83 $\mathrm{mm}$ pitch was used for circular RC columns. Three different concrete compressive strength values were selected in a range of 30-70 MPa. The thickness of the FRP tube was selected based on the common practice of limiting tube slenderness ratio or diameter-to-thickness (D/t) ratio in a range of 25-100. Four different types of FRP material with varying tensile strength values were selected. The manufacturing properties for each type of FRP materials are listed in Table 2. The column heights of 3.2, 4.8 and $6.4 \mathrm{~m}$ were considered for the single-column

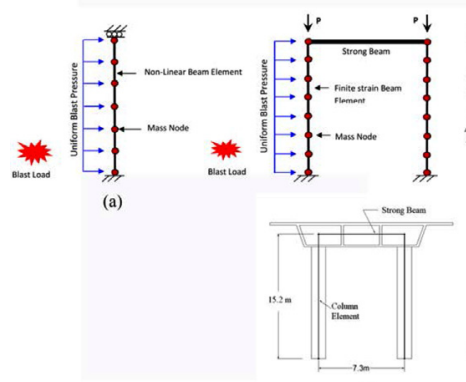

(b)

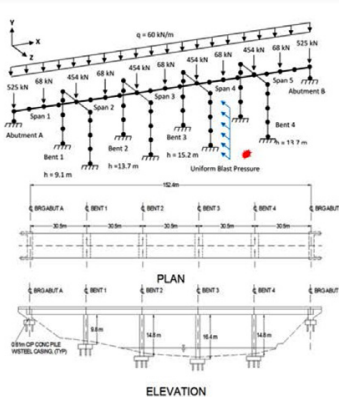

(c)

Figure 7: Finite element models used for the parametric study. 
model and 7.6, 11.4 and $15.2 \mathrm{~m}$ of column heights were studied for the pier frame model. The effect of the structural damping ratio within a range of $0.03-0.08$ was investigated. Three bomb charge weights of 227, 454, and $1814 \mathrm{~kg}$ of equivalent amount of TNT were selected for blast loading. To limit the size of the case study matrix, only one parameter at a time was considered as variable. For each parameter, several values were selected in the practical range, with one identified as the reference or base value, which was kept constant for studying the effect of other parameters. The shaded areas in Table 1 represent the base value of each parameter for single-column and pier frame models.

\subsection{Entire bridge model}

The entire bridge model was adopted from a case study by the NCHRP Project 12-49, which was prepared by BERGER/ABAM Engineers [26]. The bridge includes five equal 30.5-m long spans, with four intermediate bents with $9.8,14.8,16.4$, and $14.8 \mathrm{~m}$ heights. The plan and elevation of the bridge are presented in Fig. 7(c). A series of bridge models with FRRC columns of different FRP tube thicknesses were developed and analyzed under the effect of single and multiple blast loadings. The FRRC columns in retrofitted bridge models had a 1.17-m diameter circular section with twenty No. 25 longitudinal steel bars. The steel bars were placed at $50 \mathrm{~mm}$ clear spacing from the inside surface of the FRP tube. No transverse steel reinforcement was used in the FRRC columns due to the confinement effects and shear resistance of FRP tubes. A three-dimensional model was assembled for the whole bridge structure to take

Table 1: Parameter matrix for single column and pier frame.

\begin{tabular}{|c|c|c|c|c|c|}
\hline \multirow{2}{*}{$\begin{array}{l}\text { Parameters } \\
\text { FRP wrap thickness(D/t) }\end{array}$} & \multicolumn{5}{|c|}{ Cases } \\
\hline & $\mathrm{RC}$ & 100 & 75 & 50 & 25 \\
\hline FRP type $\left(f_{\text {frp }}\right)$ & A & B & $\mathrm{C}$ & $\mathrm{D}$ & $\mathrm{E}$ \\
\hline Damping ratio $(\xi)$ & 0 & 0.03 & & 0.05 & 0.08 \\
\hline Longitudinal reinforcement ratio $(\rho)$ & $1.26 \%$ & & $2.3 \%$ & & $3.6 \%$ \\
\hline Bomb weight of equivalent TNT (W) & $227 \mathrm{~kg}$ & & $454 \mathrm{~kg}$ & & $1814 \mathrm{~kg}$ \\
\hline Type of column & \multicolumn{3}{|c|}{$\mathrm{RC}$} & \multicolumn{2}{|c|}{ FRRC } \\
\hline Shape of cross section & \multicolumn{3}{|c|}{$\begin{array}{c}900 \times 500 \mathrm{~mm} \text { for rectangular } \\
\text { shape }\end{array}$} & \multicolumn{2}{|c|}{$\begin{array}{l}387.5 \mathrm{~mm} \text { diameter } \\
\text { for circular shape }\end{array}$} \\
\hline
\end{tabular}

Table 2: Mechanical properties for different FRP materials.

\begin{tabular}{llll}
\hline FRP materials & $\begin{array}{l}\text { Tensile strength } \\
(\mathrm{MPa})\end{array}$ & $\begin{array}{l}\text { Elastic modulus } \\
(\mathrm{GPa})\end{array}$ & Ultimate strain (\%) \\
\hline Type A (Zhu ) [7] & 234 & 15 & 1.6 \\
Type B (Shaat and Fam [29]) & 269 & 14 & 1.9 \\
Type C (Shaat and Fam [29]) & 510 & 230 & 0.3 \\
Type D (Teng and Hu [30]) & 1,825 & 80 & 2.3 \\
Type E (Kaul et al. [31]) & 3,030 & 246 & 1.7 \\
\hline
\end{tabular}


into account both in-plane and out-of-plane analyses. Similar to the single-column and pier frame models, the bridge columns were modeled using mass nodes and finite strain beam elements. The bridge superstructure in the longitudinal direction was divided into four beam elements per span along the centroid of the superstructure. The pier caps were modeled as single-line beam elements at the centerline of the box girder. A rigid column link was modeled to fill the gap between the column top and the centerline of the box girder. The mass and the dead load of the structure were lumped at the nodes of the model (see Fig. 7(c)). The analysis procedure was the same as that applied in the previous simulation models.

The investigated parameters in the bridge model included the FRP wrap thickness, type of blast loading (uniform and multiple), and bomb charge weight, as shown in Table 3. Type E FRP material (see Table 2) and a damping ratio of 0.02 were used for all bridge models. For the single blast loading case, a uniform blast pressure in the transverse direction of the bridge was assumed to act on the most vulnerable, i.e. the tallest, pier frame. For the multiple-blast loading case, a uniform blast pressures in the transverse direction was applied simultaneously on all four bents, with the same bomb charge weights and stand-off distances. The uplift effect on the bridge deck, which may be produced from below-deck blast pressure, was not taken into account in this study.

\subsection{Results and discussions}

The results of the parametric study are presented for each parameter in terms of the minimum safe stand-off distanceunder three bomb charge weights of 227, 454, and $1814 \mathrm{~kg}$. The bomb distances less than the safe stand-off distance result in structure failure.

Figure 8 represents the effect of concrete compressive strength on the blast resistance of rectangular and circular RC and FRRC columns in terms of the minimum safe stand-off distance for different bomb sizes. It is obvious from the graphs that the FRP wrap provides a significant improvement in the dynamic performance of both the column and pier frame regardless of the concrete strength. The figure shows almost a linear relationship between the blast resistance capacity and concrete compressive strength. High-strength concrete columns and pier frames are shown to provide higher blast resistance capacity than those with normal strength concrete when subjected to the same blast loading. It should be noted that blast loading is assumed to be parallel to the longer axis of the cross section. Therefore, the rectangular shape has a higher sectional capacity compared with the circular shape, which resulted in the higher blast resistance in columns with rectangular cross sections.

Figure 9 shows the effect of the steel reinforcement ratio on the blast-resistance of RC and FRRC columns of both single-column and pier frame models. The relationship between the reinforcement ratio and the safe stand-off distance is linear for the lower charge weights, whereas nonlinearity is observed for the higher charge values. The relatively steep slope implies that the reinforcement ratio has a great impact on the blast-resistance capacity of the

Table 3: Parameter matrix for the entire bridge model.

\begin{tabular}{llcccc}
\hline Parameters & \multicolumn{5}{c}{ Cases } \\
\hline FRP wrap thickness (D/t) & RC & 100 & 75 & 50 & 25 \\
Bomb weight of equivalent TNT (W) & $227 \mathrm{~kg}$ & $454 \mathrm{~kg}$ & \multicolumn{2}{c}{$\begin{array}{c}1,814 \mathrm{~kg} \\
\text { Type of loading }\end{array}$} & \multicolumn{2}{c}{ Single } & & \multicolumn{2}{c}{ Multiple } \\
\hline
\end{tabular}



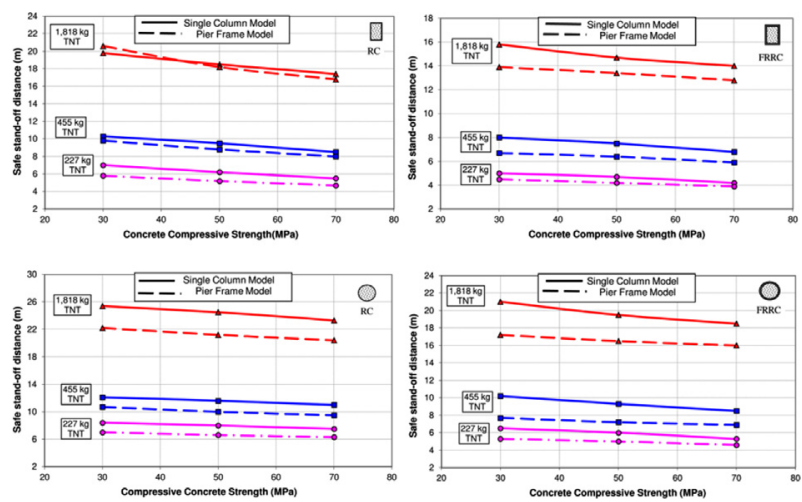

Figure 8: Effect of concrete compressive strength on safe stand-off distance.
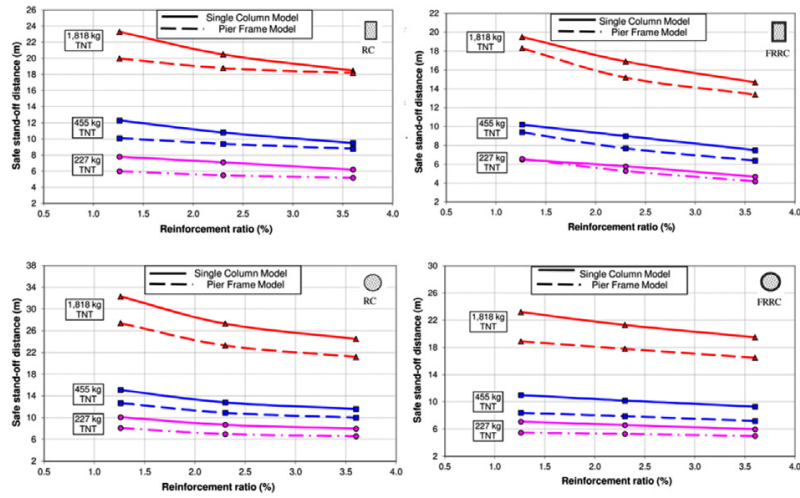

Figure 9: Effect of reinforcement ratio on safe stand-off distance.

structures, especially in the range between $1.26 \%$ and $2.3 \%$. The figure also shows that the application of FRP retrofitting reduced the minimum safe stand-off distance up to $29 \%$ and $25 \%$ for single-column and pier frame models, respectively.

Increasing FRP tensile strength improves the blast resistance of both single columns and pier frames, while decreasing the safe stand-off distances. The variation of safe stand-off distance values with different FRP materials having different tensile strengths are presented in Fig. 10(a). Furthermore, the blast-resistance of both single-column and pier frame structures is proportional to the thickness of FRP wrap irrespective of the shape of the cross section, as shown in Fig. 10(b). The results indicate that increasing FRP wrap thickness greatly enhances the blast resistance of these structures.

The minimum safe stand-off distance for shorter FRP-retrofitted columns decreased significantly as compared with the taller columns. Reducing the column height from 6.4 to $3.2 \mathrm{~m}$, the safe stand-off distance for single-column models decreased by 25\% (Fig. 11(a)), while the minimum safe stand-off distance for half-height $(7.6 \mathrm{~m})$ piers decreases by about $8 \%$, as compared with full-height $(15.2 \mathrm{~m})$ pier frames (Fig. 11(b)).

The blast resistance of both single-column and pier frame structures improved significantly after the application of higher damping ratios (Fig. 12). This implies that installing a dynamic damping device on key members may effectively enhance the blast-resistance capacity of concerned structures. 

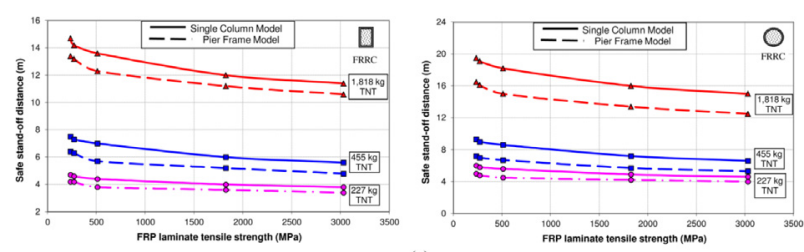

(a)
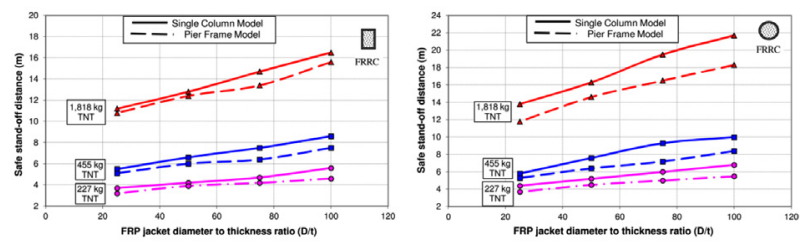

(b)

Figure 10: (a) Effect of FRP tensile strength on safe stand-off distance and (b) effect of FRP thickness on the safe stand-off distance.
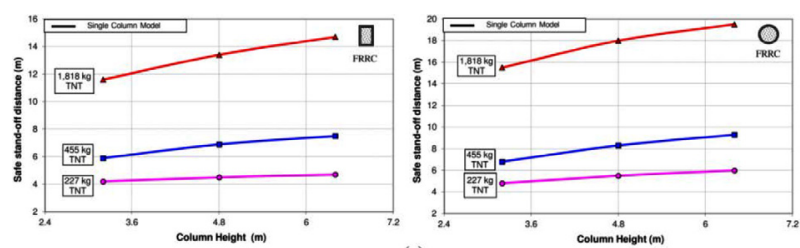

(a)

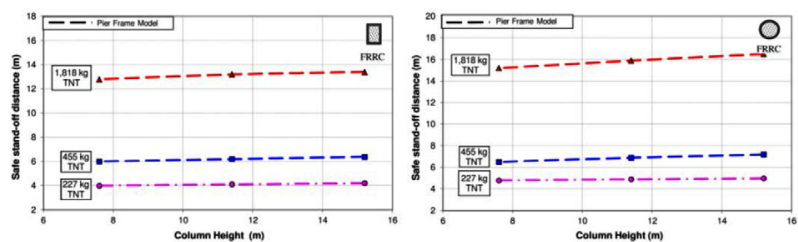

(b)

Figure 11: Effect of different column heights on safe stand-off distance: (a) single-column models and (b) pier frame models.
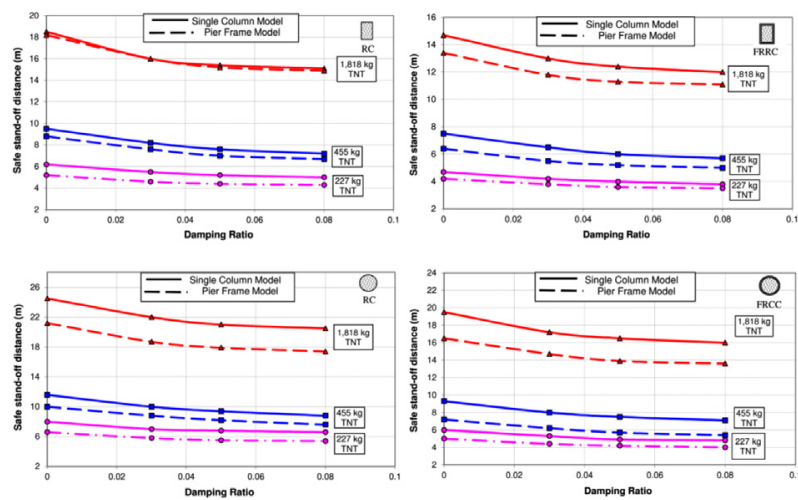

Figure 12: Effect of damping ratio on safe stand-off distance. 


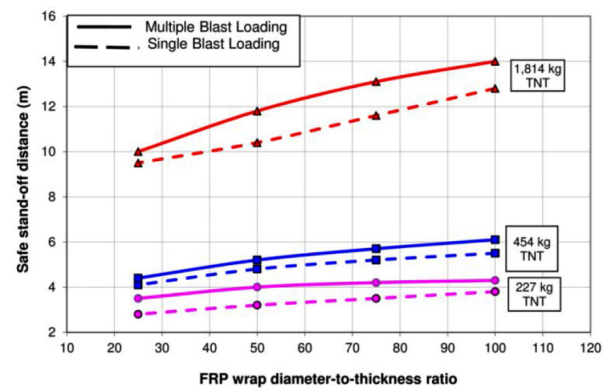

Figure 13: Effect of FRP thicknesses on minimum safe stand-off distance of entire bridge under single and multiple blastloading.

The effect of FRP jacket thickness on the blast resistance of the full bridge case study for three different bomb charge weights under single or multiple blast loadings is presented in Fig. 13. The relation between FRP diameter-to-thickness ratio and the safe stand-off resistance is almost linear at lower charge weights, with some nonlinearity at higher charges. It is also clear that a single explosion near the most vulnerable pier frame has almost the same adverse impact as multiple simultaneous explosions near all bents. The difference is obviously more pronounced at higher charge weights.

\section{DESIGN EQUATIONS}

Based on the parametric study results, predictive equations with multiple linear regression and high order terms were developed statistically for single columns subjected to blast loading. The equations correlate the safe stand-off distance (SSD) with concrete compressive strength $\left(f_{c}^{\prime}\right)$, steel reinforcement ratio $\left(\rho_{s}\right)$, FRP diameter-to-thickness ratio $(D / t)$, tensile strength $\left(f_{\text {frp }}\right)$, column length-to-diameter ratio $(L / D)$, damping ratio $(\xi)$, and bomb weight $(W)$, as

$$
\begin{aligned}
S D= & a_{0}-a_{1} f_{c}^{\prime}-a_{21} \rho_{s}+a_{22}\left(\rho_{s}\right)^{2}+a_{31} W-a_{32}(W)^{2} \\
& +a_{41}(L / D)-a_{42}(L / D)^{2}-\frac{a_{51}}{(D / t)}+\frac{a_{52}}{(D / t)^{2}}-a_{61} f_{f r} \\
& +a_{62}\left(f_{f r p}\right)^{2}-a_{71} \xi+a_{72} \xi^{2}
\end{aligned}
$$

The coefficients of independent variables in the above predictive equation are listed in Table 4 for single rectangular and circular columns, using the statistical software package SPSS 11.5 [27].

To examine the sensitivity of the blast resistance to each parameter, the percent contributions of the parameters in the design equations are plotted in Fig. 14 with their mean, minimum, and maximum values for single rectangular and circular columns. The high and low contributions were obtained by the maximum and minimum values of the concerned parameters combined with the maximum and minimum values of all other parameters, respectively. It appears that concrete compressive strength has the least contribution to the safe stand-off distance, while bomb weight has the largest. It is also apparent that within the studied range for each parameter, contributions from concrete compressive strength and FRP diameter-to-thickness ratio have the least and highest variations, respectively. 
Table 4: Coefficients of dependent variables in non-optimized and optimized models.

\begin{tabular}{|c|c|c|c|c|c|c|}
\hline & & & & Coeff & cients & \\
\hline & dependent va & Iriables & Un-optimiz & zed model & Optimized & model \\
\hline Parameter & Coefficient & Range & $\begin{array}{l}\text { Rectangular } \\
\text { column }\end{array}$ & $\begin{array}{l}\text { Circular } \\
\text { column }\end{array}$ & $\begin{array}{l}\text { Rectangular } \\
\text { column }\end{array}$ & $\begin{array}{l}\text { Circular } \\
\text { column }\end{array}$ \\
\hline Constant & $a_{0}$ & N/A & 5.25 & 6.77 & 1.64 & 1.82 \\
\hline$f_{c}^{\prime}(\mathrm{MPa})$ & $a_{1}$ & $30-70$ & 0.04 & 0.04 & $5.26 \times 10^{3}$ & $4.26 \times 10^{3}$ \\
\hline$\rho_{s}$ & $a_{21}$ & $0.0126-0.036$ & 205.95 & 320.00 & N/A & 12.09 \\
\hline$\left(\rho_{s}\right)^{2}$ & $a_{22}$ & $\begin{array}{l}1.59 \times 10^{4} \text { to } \\
1.3 \times 10^{3}\end{array}$ & 1508.52 & 3631.75 & 302.92 & N/A \\
\hline$W(\mathrm{~kg})$ & $a_{31}$ & $227-1814$ & 0.01 & 0.02 & $2.89 \times 10^{3}$ & $2.67 \times 10^{3}$ \\
\hline$W^{2}(\mathrm{~kg})$ & $a_{32}$ & $\begin{array}{l}5.15 \times 10^{4} \text { to } \\
3.29 \times 10^{6}\end{array}$ & $3.89 \times 10^{-6}$ & $3.34 \times 10^{6}$ & $9.90 \times 10^{7}$ & $8.50 \times 10^{7}$ \\
\hline$L / D$ & $a_{41}$ & $\begin{array}{l}3.55-7.11 \\
\text { (Rectangular) } \\
8.26-16.52 \\
\text { (Circular) }\end{array}$ & 1.49 & 0.77 & 0.06 & 0.04 \\
\hline$(L / D)^{2}$ & $a_{42}$ & $\begin{array}{l}\text { 12.6-50.55 } \\
\text { (rectangular) } \\
68.23-2555.3 \\
\text { (circular) }\end{array}$ & 0.08 & 0.02 & N/A & N/A \\
\hline $1 /(D / t)$ & $a_{51}$ & $0-0.04$ & 188.58 & 271.28 & 23.26 & 27.50 \\
\hline $1 /(D / t)^{2}$ & $a_{52}$ & $0-0.0016$ & 1889.61 & 2542.50 & 197.21 & 198.69 \\
\hline$f_{f r p}(\mathrm{MPa})$ & $a_{61}$ & $234-3030$ & $2.00 \times 10^{-3}$ & $2.00 \times 10^{3}$ & $1.20 \times 10^{4}$ & $1.30 \times 10^{4}$ \\
\hline$\left(f_{f r p}\right)^{2}(\mathrm{MPa})$ & $a_{62}$ & $\begin{array}{l}5.5 \times 10^{4} \text { to } \\
9.2 \times 10^{6}\end{array}$ & $3.47 \times 10^{-7}$ & $3.49 \times 10^{7}$ & N/A & N/A \\
\hline$\Xi$ & $a_{71}$ & $0-0.08$ & 51.12 & 61.50 & 3.71 & 3.74 \\
\hline$\xi^{2}$ & $a_{72}$ & $0-0.0064$ & 322.67 & 382.87 & N/A & N/A \\
\hline
\end{tabular}

To optimize the predictive model, stepwise regression and the Box-Cox transformation method were used to achieve a closer normal distribution of regression residuals with significant independent variables. Box and Cox proposed a family of transformations [28], which include reciprocals, logarithms, and square roots, in a general form as follows:

$$
y(\lambda)= \begin{cases}\frac{y^{\lambda}-1}{\lambda}, & \lambda \neq 0 \\ \log y, & \lambda=0\end{cases}
$$

where parameter $\lambda$ is determined by the maximum log-likelihood. The coefficients of independent variables in the optimized equations are listed in Table 4 for $\lambda=0.1$.

To examine the degree of fitness of the un-optimized and optimized multiple regression models, the predicted safe stand-off distances obtained from design equations and the original safe stand-off distances obtained from the FE analysis are scatter-plotted in Fig. 15 for 


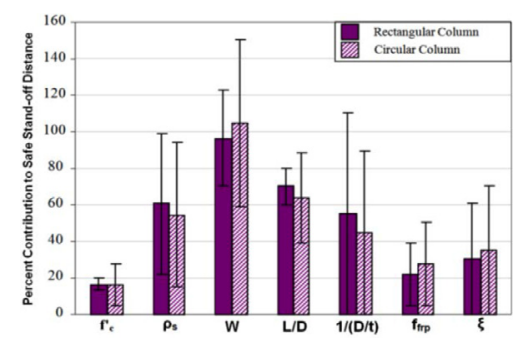

Figure 14: Percent contribution to safe stand-off distance in single rectangular and circular columns.

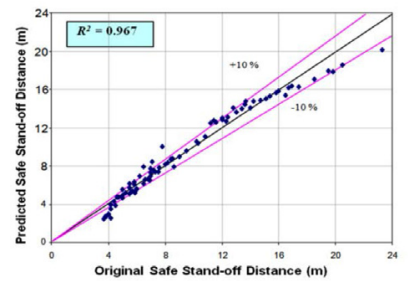

(a)

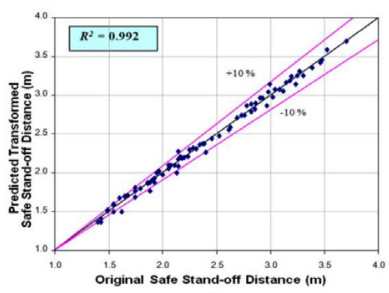

(b)

Figure 15: Predicted versus original safe stand-off distance for single rectangular columns: (a) original form in non-optimized model and (b) Box-Cox-transformed form in optimized mode.

single rectangular column. It is clear that most of the predicted values are within $\pm 10 \%$ of their original values. The high correlation between the results predicted by the proposed models and those resulted from the verified FE models, which covers the whole practical ranges of parameters, testifies the validity of both un-optimized and optimized design equations. Indeed, the better correlation between the predicted and original values in Fig. 15(b) indicates the higher accuracy of the multiple linear regression model optimized by the stepwise and Box-Cox transformation methods.

\section{CONCLUSIONS}

Using a verified novel simplified FE model, a thorough parametric study on the blast-resistance of FRP-retrofitted bridge structures was carried out. Using the results of the parametric study, predictive equations were developed for FRP retrofit design against blast loading. The following conclusions may be drawn from the present study:

The simplified equivalent I-section with a virtual material provides a fast and robust alternative to sophisticated 3-D FE modeling for concrete structures under blast loading.

Retrofitting the RC columns of bridge structures with FRP wraps can significantly enhance their blast resistance. The results of the parametric study showed that the blast resistance of FRP-retrofitted columns is dependent on concrete compressive strength, internal steel reinforcement, column length-to-diameter ratio, FRP diameter-to-thickness ratio and tensile strength, and damping ratio. Among these dominant parameters, the thickness and tensile strength of the FRP wrap have the highest effect, while the strength of the concrete has the least effect on the dynamic response of FRP-retrofitted columns under blast loading. Therefore, $D / t$ ratio and $f_{f r p}$ should be selected using a cost-benefit analysis.

In comparison with multiple explosives, even one explosive charge placed at or near critical areas of a bridge may still produce a devastating impact on the entire bridge. 
Finally, based on the parametric study results, predictive equations with multiple linear regression and high order terms were developed statistically, which proved to be suitable for the FRP retrofit design of single columns against blast loading.

\section{ACKNOWLEDGEMENTS}

Financial support for this study was provided by the Federal Highway Administration through a grant from the University Consortium for Intermodal Transportation Safety and Security at the Florida Atlantic University in Boca Raton, FL. The contribution of the sub-consultant, Dr. Faris Malhas of then at the University of North Florida, currently at Bowling Green State University, is also acknowledged. Findings and opinions expressed here, however, are those of the authors alone, and not necessarily the views of the sponsoring agencies.

\section{REFERENCES}

[1] Williams, G.D. \& Williamson, E.B., Response of reinforced concrete bridge columns subjected to blast loads. Journal of Structural Engineering, 137(9), pp. 903-913, 2011. doi: http://dx.doi.org/10.1061/(asce)st.1943-541x.0000440

[2] Winget, D.G., Marchand, K.A. \& Williamson, E.B., Analysis and design of critical bridges subjected to blast loads. Journal of Structural Engineering, 131(8), pp. 1243 1255, 2005. doi: http://dx.doi.org/10.1061/(asce)0733-9445(2005)131:8(1243)

[3] ASCE, The Oklahoma city building: improving building response through multi-hazard mitigation. Report for FEMA. Report no. 277, New York, NY, 1996.

[4] Malvar, L.J., Crawford, J.E. \& Morrill, K.B., Use of composites to resist blast. Journal of Composites for Construction, 11(6), pp. 601-610, 2007. doi: http://dx.doi. org/10.1061/(asce)1090-0268(2007)11:6(601)

[5] Dumas, P., Structural retrofitting using fiber reinforced polymers. Ms Thesis, Massachusetts Institute of Technology, Cambridge, MA, 2012.

[6] Mirmiran, A. \& Shahawy, M., Composite pile: a successful drive. Concrete International, 25(3), pp. 89-94, 2003.

[7] Zhu, Z., Joint construction and seismic performance of concrete-filled fiber reinforced polymer tubes. PhD Dissertation, North Carolina State University, Raleigh, NC, 2004.

[8] Elsanadedy, H., Almusallam, T., Abbas, H., Al-Salloum, Y., Alsayed, S. \& Al-Haddad, M., Effect of blast loading on CFRP retrofitted RC columns. IMPLAST 2010 Conference, Providence, Rhode Island, October, pp. 12-14, 2010. doi: http://dx.doi. org/10.1590/s1679-78252011000100004

[9] Crawford, J.E., Malvar, L., Morrill, K.B. \& Ferritto, J.M., Composite retrofits to increase the blast resistance of reinforced concrete buildings. 10th International Symposium Interaction of the Effects of Munitions with Structures, P-01-13, San Diego, CA, 2001.

[10] Williamson, E.B. \& Winget, D.G., Risk management and design of critical bridges for terrorist attacks. Journal of Bridge Engineering, 10(1), pp. 96-106, 2005. doi: http:// dx.doi.org/10.1061/(asce)1084-0702(2005)10:1(96)

[11] Hamed, E. \& Rabinovitch, O., Dynamic behavior of reinforced concrete beams strengthened with composite materials. Journal of Composites for Construction, 9(5), pp. 429-440, 2005. doi: http://dx.doi.org/10.1061/(asce)1090-0268(2005)9:5(429)

[12] Mosalam, K.M. \& Mosallam, A.S., Nonlinear transient analysis of reinforced concrete slabs subjected to blast loading and retrofitted with CFRP composites. Composites Part B: Engineering, 32(8), pp. 623-636, 2001. doi: http://dx.doi.org/10.1016/s1359-8368(01)00044-0

[13] Shi, Y., Li, Z. \& Hao, H., A new method for progressive collapse analysis of RC frames under blast loading. Engineering Structures, 32(6), pp. 1691-1703, 2010. doi: http:// dx.doi.org/10.1016/j.engstruct.2010.02.017 
[14] Nam, J., Kim, H., Kim, S., Kim, J.J. \& Byun, K.J., Analytical study of finite element models for FRP retrofitted concrete structure under blast loads. International Journal of Damage Mechanics, 18(5), pp. 461-490, 2009. doi: http://dx.doi.org/10.1177/1056789507088339

[15] Ngo, T., Mendis, P., Gupta, A. \& Ramsay, J., Blast loading and blast effects on structures - an overview. Electronic Journal of Structural Engineering, 7, pp. 76-91.2007.

[16] Bentz, E.C. \& Collins, M.P., Response 2000. Software Program for Load-Deformation Response of Reinforced Concrete Section, 2000, available at: http://www.ecf.utoronto. $\mathrm{ca} / \sim$ bentz/news.shtml.

[17] ANSYS, Inc., ANSYS Version 8.0, ANSYS, Inc.: Canonsburg, PA, 2003. doi: http:// dx.doi.org/10.1016/j.jmbbm.2014.01.005

[18] CEB-FIP, Design of concrete structures. CEB-FIP-Model-Code, British Standard Institution: London, UK, 1990. doi: http://dx.doi.org/10.1680/fiphopd.35447

[19] Ngo, T.D., Behaviour of high strength concrete subject to impulsive loading, PhD Dissertation, The University of Melbourne, Australia, 2005.

[20] Scott, B.D., Park, R. \& Priestley, M., Stress-strain behavior of concrete confined by overlapping hoops at low and high strain rates. ACI Journal, 79(1), pp. 13-27, 1982. doi: http://dx.doi.org/10.14359/10875

[21] Soroushian, P. \& Choi, K., Steel mechanical properties at different strain rates. Journal of Structural Engineering, 113(4), pp. 63-672, 1987. doi: http://dx.doi.org/10.1061/ (asce)0733-9445(1987)113:4(663)

[22] Shao, Y. \& Mirmiran, A., Nonlinear cyclic response of laminated glass FRP tubes filled with concrete. Composite Structures, 65(1), pp. 91-101, 2004. doi: http://dx.doi. org/10.1016/j.compstruct.2003.10.009

[23] Kuksenko, V.S. \& Tamuzs, V., Fracture Micromechanics of Polymer Materials, Martinus Nijhoff Publishers: The Hague (Series on Fatigue and Fracture), 1981. doi: http:// dx.doi.org/10.1007/978-94-017-1597-3

[24] AT Blast Software, Applied Research Associates of Vicksburg, MS, available at: http:// www.ara.com/products/AT-blast.htm.

[25] Ngo, T., Mendis, P., Teo, D. \& Kusuma, G., Behavior of high-strength concrete columns subjected to blast loading, 7th International Conference on Steel-Concrete Composite Structures, Sydney, Australia, pp. 23-25, ASCCS, 2003.

[26] Berger/Abam Engineers, Seismic Design of Bridges - Design Example No. 8. Report for National Cooperative Highway Research Program (NCHRP), Report no. A99067, Project 12-49, Washington, DC, 2001.

[27] SPSS, Inc., SPSS 11.5 for Windows, SPSS, Inc.: Chicago, IL. doi: http://dx.doi. org/10.1177/106480460100900407

[28] Box, G.E.P. \& Cox, D.R., An analysis of transformation (with discussion). Journal of Royal Statistical Society, Series B, 26, pp. 211-252, 1964.

[29] Shaat, A. \& Fam, A., Effectiveness of different composite materials for repair of steel bridge girders, 3rd International Conference on FRP Composites in Civil Engineering, Miami, FL, pp. 721-724, CICE, 2006.

[30] Teng, J.G. \& Hu, Y.M., Theoretical model for FRP-confined circular concrete-filled steel tubes under axial compression, 3rd International Conference on FRP Composites in Civil Engineering, Miami, FL, pp. 503-506, CICE, 2006.

[31] Kaul, R., Ravindrarajah, R.S. \& Smith, S.T., Deformational behavior of FRP confined concrete under sustained compression, 3rd Int'l. Conf. FRP Composites in Civil Engineering, Miami, FL, pp. 207-210, CICE, 2006. 